\title{
THE EFFECTIVENESS OF DIRECT AGING ON INCONEL 718 FORGINGS PRODUCED AT HIGH STRAIN RATES AS OBTAINED ON A SCREW PRESS
}

\author{
W. Horvath, W. Zechner, J. Tockner, M. Berchthaler, G. Weber and E.A. Werner† \\ BÖHLER Schmiedetechnik GmbH \& Co KG, \\ Mariazellerstr.25, A-8605 Kapfenberg, Austria,whorvath@bstg.buag.co.at \\ $\uparrow$ Lehrstuhl für Mechanik and Christian-Doppler Laboratorium, TU-München, \\ Boltzmannstr. 15, D-85747 Garching, Germany
}

\begin{abstract}
Screw press forging experiments on industrial equipment are carried out in order to evaluate the potential of this process for the production of jet engine disks from the direct aged nickel base alloy IN718. Metallography, electron microscopy and elevated temperature tensile tests are performed to analyse and quantify the strength improvements due to direct aging. The results of these analyses clearly demonstrate that the production of direct aged IN718 turbine disks is possible on a screw press.
\end{abstract}

Superalloys $718,625,706$ and Various Derivatives

Edited by E.A. Loria

TMS (The Minerals, Metals \& Materials Society). 2001 


\section{Introduction}

The direct age process of Inconel (IN) 718 forgings was developed by General Electric and Wyman Gordon during the 1970s and 1980s and was published comprehensively in the Superalloys Proceedings 1989 [1]. Direct aging (DA) is a synonym for hardening of an Inconel 718 forging after the forming operation and applying a two step aging procedure common for Inconel 718, yielding solution treated and aged (STA) materials. Due to direct aging additional strength at elevated temperature and improved low-cycle fatigue properties can be achieved, while maintaining the excellent creep strength of the material. Hence, the process results in a pronounced exploitation of the alloy's strength potential. Industrial DA processing is focused primarily on hydraulic press forging [1]. In the present work the effectiveness of direct aging after screw press forging of pancakes is investigated and, therefore, covers the strain rate regime above that of hydraulic presses. The influences of forging below and above the $\delta$-solvus temperature, effective strain, number of forging steps and the post forge cooling rate on the microstructure and the tensile properties at elevated temperature are investigated. From micrographs taken in a transmission electron microscope (TEM) from selected material conditions the relevant mechanisms responsible for hardening of the material will be identified.

\section{Experiments}

An 8 inch diameter starting material with an initial average grain size of ASTM 7.5 and a $\delta$-solvus temperature of $995^{\circ} \mathrm{C}$ was investigated in the present work. Preforms (thickness $90 \mathrm{~mm}$ ) for pancake forging were designed by using the FEM Software DEFORM ${ }^{\mathrm{TM}}$ and machined out of the billet material. Goal of the simulation supported design was the reduction of die chill before the onset of the forging operation so ensuring sufficiently large portions undergoing homogeneous strain, strain rate and temperature histories. Average strain rates of $7 \mathrm{~s}^{-1}$ were realized in the screw press forging operations. Three forging temperatures were chosen $\left(990^{\circ} \mathrm{C}, 1000^{\circ} \mathrm{C}\right.$ and $\left.1030^{\circ} \mathrm{C}\right)$ and strain levels of $0.3,0.4,0.5$ and $\mathrm{I}$ were adjusted in the forged parts. Forging was done on a $315 \mathrm{MN}$ screw press in one single step to final strains of $0.3,0.4,0.5$, and 1 . Additionally, two step forging sequences were performed to obtain a total strain value of $1(0.5$ - reheating -0.5$)$ at $990^{\circ} \mathrm{C}$ and $1030^{\circ} \mathrm{C}$. The final thickness of the forged pancakes varied between $32 \mathrm{~mm}$ to $64 \mathrm{~mm}$. The pancakes forged at $1000^{\circ} \mathrm{C}$ were quenched in water and cooled in air, all other parts were quenched in water. The complete set of processing variables is listed in Tab. I. Then a two step aging treatment of all parts was done according to [1], which consisted of $718^{\circ} \mathrm{C} / 8 \mathrm{~h} / \mathrm{FC}$ and $621{ }^{\circ} \mathrm{C} / 8 \mathrm{~h} / \mathrm{AC}$. Reference parts were forged at $1000^{\circ} \mathrm{C}$ and were solution annealed at $980^{\circ} \mathrm{C} / 1 \mathrm{~h} / \mathrm{AC}$ prior to the two step aging treatment in order to quantify the strength improvement resulting from direct aging. Grain size was used as indicator for the microstructural development introduced by the thermomechanical treatments. Tensile specimens were oriented in radial direction and positioned so to ensure the gauge length was located within the homogeneous pancake portion. Elevated temperature tensile tests done at $400^{\circ} \mathrm{C}, 455^{\circ} \mathrm{C}$, and $650^{\circ} \mathrm{C}$ give information on the effectiveness of direct aging of screw press processed parts.

The degree of recrystallization and the influence of the thermomechanical treatment on dislocation structures were monitored in a Jeol transmission electron microscope operated at a maximum voltage of $200 \mathrm{kV}$. Preperation of the specimens for the TEM-analysis consisted of mechanical grinding and electropolishing of thin disks taken from selected pancakes. The latter operation of polishing and final thinning was done with a Struers Lectropol 5 equipment using the Struers electrolyte $\mathrm{A} 8$ cooled down to $12^{\circ} \mathrm{C}$. 
Table I Forging parameters for direct age experiments (WQ = water quench, $\mathrm{AC}=$ air cooling).

\begin{tabular}{|c|c|c|c|c|c|}
\hline Condition & $\begin{array}{c}\text { Forging Temperature } \\
{\left[{ }^{\circ} \mathrm{C}\right]}\end{array}$ & Effective Strain & Forging Steps & Strain/Step & Cooling \\
\hline $\mathrm{A}$ & 990 & 0.5 & 1 & 0.5 & WQ \\
\hline $\mathrm{B}$ & 990 & $\mathrm{l}$ & 2 & 0.5 & WQ \\
\hline $\mathrm{C}$ & 990 & 1 & 1 & 1 & WQ \\
\hline $\mathrm{D}$ & 1000 & 0.3 & 1 & 0.3 & WQ \\
\hline $\mathrm{E}$ & 1000 & 0.3 & 1 & 0.3 & $\mathrm{AC}$ \\
\hline $\mathrm{F}$ & 1000 & 0.4 & 1 & 0.4 & WQ \\
\hline $\mathrm{G}$ & 1000 & 0.4 & 1 & 0.4 & $\mathrm{AC}$ \\
\hline $\mathrm{H}$ & 1000 & 0.5 & 1 & 0.5 & WQ \\
\hline $\mathrm{I}$ & 1000 & 0.5 & 1 & 0.5 & $\mathrm{AC}$ \\
\hline $\mathrm{J}$ & 1030 & 0.5 & 1 & 0.5 & WQ \\
\hline $\mathrm{K}$ & 1030 & 1 & 2 & 0.5 & WQ \\
\hline $\mathrm{L}$ & 1030 & 1 & 1 & 1 & WQ \\
\hline
\end{tabular}

\section{Results and Discussion}

\section{Microstructure}

Figure 1 shows, that the grain size of Inconel 718 reacts to both temperature and strain variations in the course of forging on a screw press and subsequent direct aging.

The initial grain size (ASTM 7.5) could be refined continuously in single step forging operations by increasing the applied strain from 0.3 to 1 at forging temperatures close to the $\delta$-solvus according to the relation $G S_{\mathrm{ASTM}}(\epsilon)=G S_{\mathrm{ASTM}}(\epsilon=0)+0.035 * \epsilon, \epsilon$ in percent. Furthermore, no difference in grain size could be detected in parts forged to a maximum strain of 1 at $990^{\circ} \mathrm{C}$ in either one or two steps. Single step (SS) processing at $1030^{\circ} \mathrm{C}$ results in an only moderate grain refinement from ASTM 7.5 to ASTM 8. Double step (DS) forging at $1030^{\circ} \mathrm{C}$ to a final strain of 1 leaves the average grain size unaffected. With respect to the grain size, homogeneously recrystallized microstructures were produced in all the experiments which gives evidence for the occurrence of dynamic recrystallization at the applied strain rate of $7 \mathrm{~s}^{-1}$. This observation corresponds to findings of Howson and Couts [2] and Zhao and Chaudhury [3] who developed deformation maps for Inconel 718. Figure 1 also reveals that the recommended minimum grain size of ASTM 10 for optimum mechanical properties of direct aged Inconel 718 forgings [1] would require strain

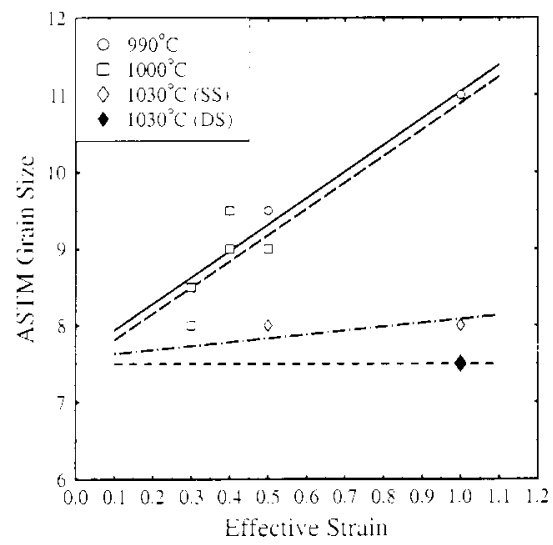

Figure 1: Grain size development of direct aged IN718 for various conditions (see Tab. I). 


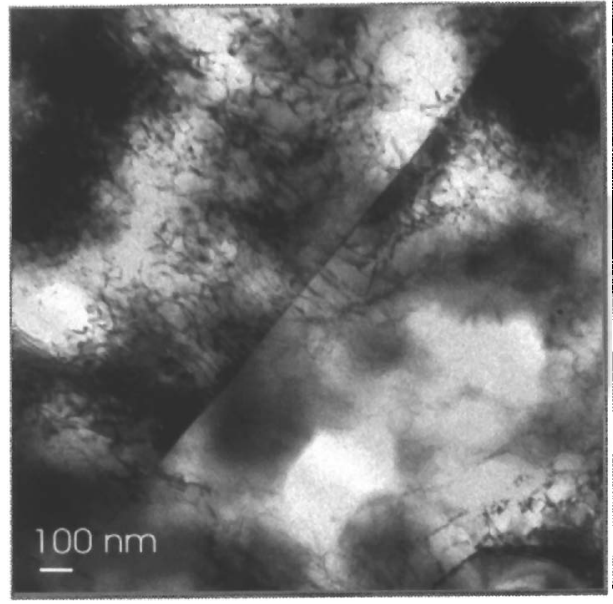

(a) Inhomogeneous distribution of dislocations.

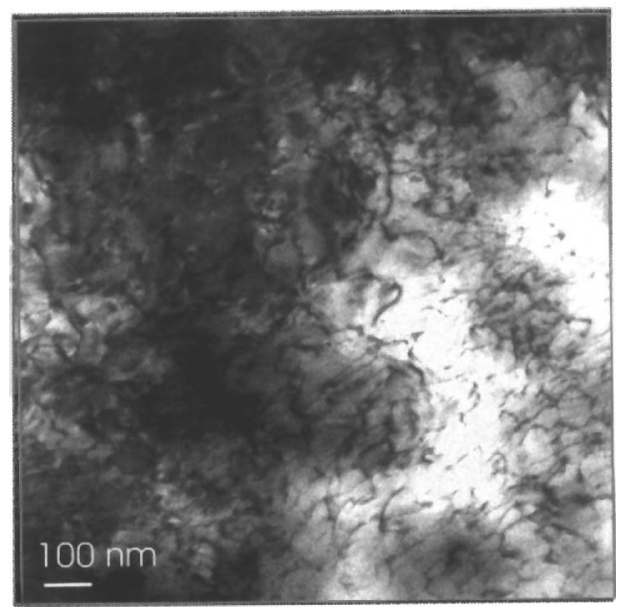

(b) Pinned and bowed out dislocations.

Figure 2: TEM images of IN7 18 in the as-forged condition $\left(990^{\circ} \mathrm{C}, \epsilon=0.5,1\right.$ stroke, WQ).

values of at least 0.7 in single step operations or a minimum of two subsequent forging steps (reheating included) at $990^{\circ} \mathrm{C}$ or $1000^{\circ} \mathrm{C}$. The marked dependence of the grain size on the strain for the material forged close to the $\delta$-solvus temperature stems from the increasing number of recrystallization nuclei due to the increase in strain and the simultaneous impediment of grain growth due to the presence of the $\delta$ phase, whereas a much lower dragging force for grain growth acts in the absence of the $\delta$ phase, i.e. when forging is done at $1030^{\circ} \mathrm{C}$ [4].

\section{Elevated temperature tensile tests}

Since the different combinations of forging temperature, the number of forging steps, and the applied strain all result in distinct microstructures in terms of grain size and $\delta$ phase distribution, the tensile test results obtained at $400^{\circ} \mathrm{C}, 455^{\circ} \mathrm{C}$, and $650^{\circ} \mathrm{C}$ (service temperature regime) are comprehensively analyzed with focus on the post-forge cooling method and are compared with results obtained on solution treated and aged Inconel 718 pancakes. Even though in the current work no optimization of the microstructure (grain size, Figure 1) was undertaken, all tensile test results are on an encouraging high level.

Yield strength, YS. The yield strength of water quenched and aged pancakes exceeds those of air cooled and aged, and of solution annealed and aged pancakes in the temperature range investigated, Figure 3 . This cannot be explained on the basis of the grain size existing at the end of the forging operation. Instead, an analysis of the as-forged microstructures in a TEM reveals, that dynamic recrystallization during the forming operation competes with the generation of dislocations by plastic deformation resulting in a non-uniform distribution of dislocations in the microstructure (Figure 2 (a)), where regions of high dislocation density coexist with almost dislocation free areas. Cooling in air instead of quenching in water provides the time necessary to rearrange the dislocations in low-energy configurations. Figure 2 (b) shows a high number of bowed out dislocation lines pinned by obstacles.

Initiation of plastic deformation requires the motion of these pinned dislocations at increased levcls of stress. For all material conditions investigated a slight drop in YS between $400^{\circ} \mathrm{C}$ and 


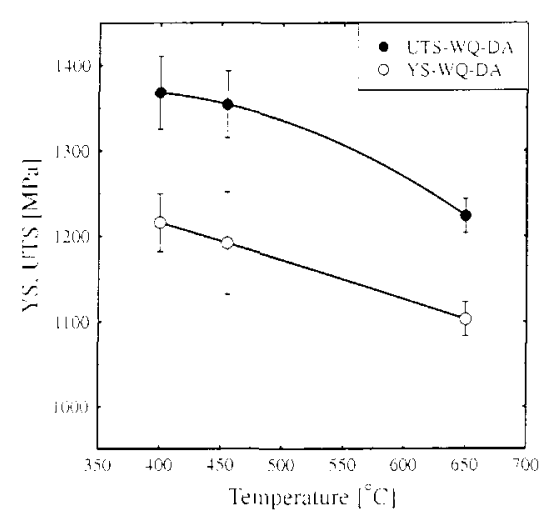

(a) Aged after water quench (WQ-DA).

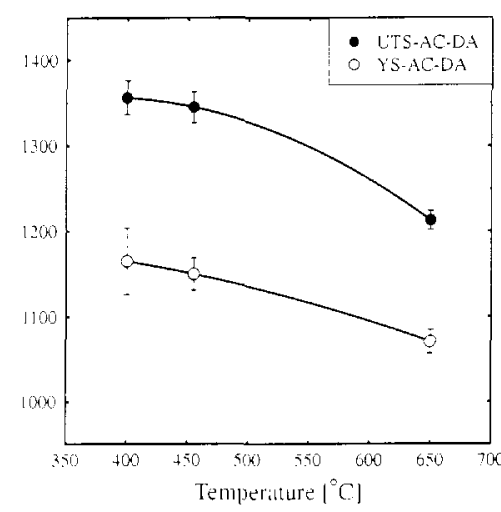

(b) Aged after air cooling (ACDA).

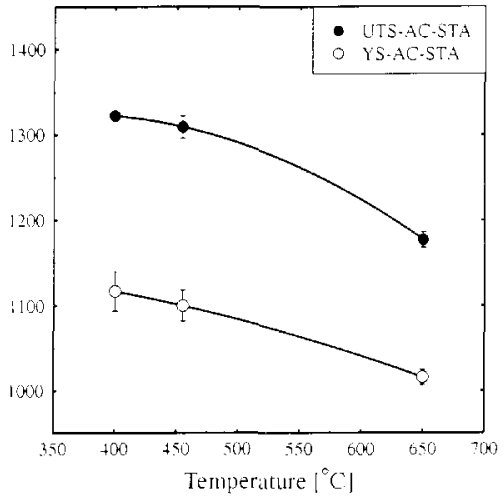

(c) Fully heat treated (AC-STA).

Figure 3:: Yield strength (YS) and ultimate tensile strength (UTS) of screw press forged IN718 pancakes.

$455^{\circ} \mathrm{C}$ is followed by a more pronounced decrease between $455^{\circ} \mathrm{C}$ and $650^{\circ} \mathrm{C}$, which is smallest for the air cooled and aged pancakes. Direct aging the air cooled forgings raise the YS by $4.7 \%$ as compared to the solution treated and aged pancakes, whereas for the water quenched and aged pancakes an improvement of $8.6 \%$ is achieved. The scatter of the YS data is largest for the water quenched and aged parts followed by the air cooled and aged pancakes. This is an indication for an increasingly inhomogeneous arrangement of dislocations and precipitates with increasing post-forge cooling rate.

Ultimate tensile strength, UTS. The influence of direct aging on the UTS is similar to that on the YS (see Figure 3). However, the relative strength improvement achievable is somewhat smaller than that observed for the YS. In the average, direct aging increases the UTS of air cooled pancakes by $2.8 \%$ and that of water quenched and aged materials by $3.7 \%$. Hence, differences in the dislocation arrangements governing the onset of plastic deformation become less important as the tensile specimens are subjected to larger plastic deformations. The dependence of the UTS on the tensile test temperature is larger than that of the YS. Again, for all test temperatures the scatter of the data is largest for the water quenched and direct aged pancakes followed by the air cooled and aged material and the solution treated and aged pancakes. A comparison of the difference between YS and UTS shows that the water quenched and direct aged material's UTS lies in average $12.4 \%$ above its YS, whereas the air cooled and aged pancakes exhibit 15.6\% between YS and UTS due to the fact, that direct aging is less effective for the air cooled material.

Elongation to fracture, A, and reduction of area, Z. For the sake of completeness the two ductility measures ( $\mathrm{A}$ and $\mathrm{Z}$ ) were determined, too. Figure 4 shows that $\mathrm{A}$ is increasing with increasing test temperature for all material conditions. Both the cooling route after forging and the subsequent heat treatments do not influence A markedly. A similar tendency was observed for $Z$. 


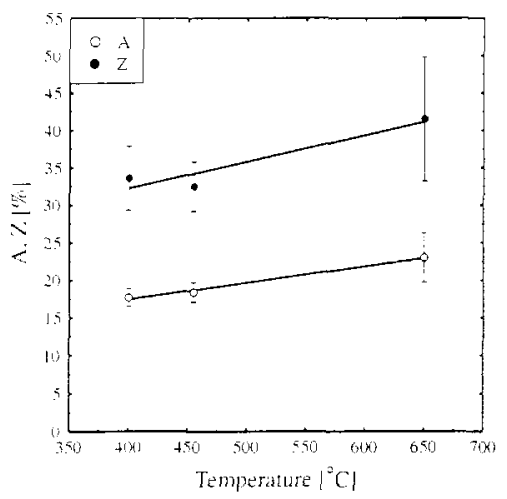

Figure 4: Ductility of screw press forged IN718 pancakes.

\section{Conclusions}

Based on data obtained from experiments performed on a $315 \mathrm{MN}$ screw press, tensile testing, light and electron optical microscopy, the following conclusions can be drawn on the effectiveness of direct aging applied to IN718 forgings:

- Multiple step forging processes are required to achieve a homogeneous and sufficiently fine grain size, which is the necessary prerequisite for the exploitation of the elevated temperature strength potential of direct aged IN718.

- Work hardened microstructures with high dislocation density have to be produced in the thermomechanical process and must be stabilized by accelerated post forge cooling.

- Even though at now the obtained yield and ultimate tensile strength improvements due to direct aging are only in the range of $4.7 \%$ to $8.6 \%$ (YS) and $2.8 \%$ to $3.7 \%$ (UTS), direct aging of screw press forged IN718 turbine disks on industrial scale is in sight.

\section{Acknowledgement}

The authors appreciate the valuable support given by the screw press staff of BÖHLER Schmiedetechnik, the TEM expertise of Dr. M. Hanzlik and the editorial contributions of A.Z. Spalek.

\section{References}

1. D.D. Krueger, The development of direct age 718 for gas turbine disk application, Superalloy 718 - Metallurgy and Application, ed. E.A. Loria (Warrendale, PA: TMS, 1989), 279-296.

2. T.E. Howson and W.H. Couts, Jr., Progress toward a deformation map for fine grain alloy 718 billet, Superalloy 718-Metallurgy and Application, ed. E.A. Loria (Warrendale, PA: TMS, 1989), 685-694.

3. D. Zhao and P.K. Chaudhury, Effect of starting grain size on as-deformed microstructure in high temperature deformation of alloy 718 , Superalloy 718,625,706 and Various Derivatives, ed. E.A. Loria (Warrendale, PA: TMS, 1994), 303-313.

4. H.P. Stüwe, Recrystallisation of Metallic Materials, ed. F. Haessner (Stuttgart, Germany: Riederer Verlag, 1978), 11-21. 